\title{
3a
}

\section{The social role of businesses and the role of the professional}

\author{
Johan Wempe
}

\section{Introduction}

For years, the business sector was held up as an example for government organizations. Businesses work much more efficiently and are much more effective. This trend resulted in a profusion of privatization operations, as well as pressure on governments to deregulate. Over the last few years, however, the image of trade and industry has suffered serious damage. This was already an issue during the mid-'90s, with Greenpeace's criticism of the sinking of the Brent Spar, and snowballed as a result of the affairs concerning Enron, Ahold and Parmalat as well as the discussion of top salaries. All these debates have seriously lowered the level of esteem for the business world. A new aspect is the role of independent supervisory organizations that publicly correct those companies. Also striking is the changed role of what was traditionally designated as the social centerfield. Social organizations openly call businesses to account for their social impact. Other social organizations focus, on the other hand, on seeking partnerships with companies in order to realize social goals together. We are seeing considerable shifts, whereby the changing position of businesses plays a central role. Twenty years ago, it was unthinkable that anyone would speak of the human-rights policy of a company. That was considered an issue for governments. What's going on?

First of all, we shall discuss three examples of social debates in which businesses play a crucial role. There is talk of a structural problem for businesses that lies at the basis and, in fact, for society as a whole.

\section{Top salaries}

In various Western countries, a discussion has broken loose on the salaries of the top management echelon. In The Netherlands, the board of the Dutch Heart Foundation reconsidered the salary that was paid to the director of the foundation, the cardiologist V. Manger Cats, when it became evident that volunteers refused to collect donations for the Heart Foundation. According to the estimate of the Dutch Heart Foundation, the commotion concerning the salary of their director was responsible for a $12.5 \%$ decrease in the annual house-to-house collection for the Heart Foundation (NRC Handelsblad, 21 May 2004). The ING Bank even received criticism from the Prime Minister for what he considered an exorbitant salary increase for the bank's administrators. And the recently appointed top man Anders Moberg of Ahold buckled under, and adapted his terms of employment when threatened with a consumer boycott. In Great Britain, the shareholders blew the whistle on chemical giant GlaxoSmithKline when it wanted to grant one of the top people an extravagant salary.

\footnotetext{
${ }^{\#}$ Rotterdam School of Management, Erasmus Universiteit Rotterdam, P.O. Box 1738, 3000 DR Rotterdam, The Netherlands. E-mail: j.wempe@fbk.eur.nl
} 
In the USA as well, the salaries and bonuses of various top entrepreneurs were the subject of a social debate.

The critics often point out the sharp contrast with the meagre results and the considerable price drops that the businesses have shown in recent times. Employees must tighten their belts. In a number of cases, this has even led to radical reorganizations and even dismissal of employees. Top managers who go home with a substantial salary increase give the wrong example, or enrich themselves at the expense of the employees, it is reasoned. It is not only about the level of the salaries, but what is also called 'a win-win situation'. When appointed, a top manager not only insists on a top salary, he also demands a golden handshake if it goes wrong. Even if he does not achieve anything, he still leaves with a pile of money.

In defence, it is maintained that the Board of Commissioners determine the salaries. In order to do so, they often set up a remuneration committee, which looks at developments among similar international companies. The world is the playing field of multinationals. In order to attract managers who can run an international company, you must offer attractive salaries in the international playing field. If, for a company such as Ahold, which is on the edge of the abyss after the fraud affair, you want to attract a new CEO who can save the company from ruin, you will have to dig deep into your pockets. Another argument in this regard is the high casualty risk. Today, if a top entrepreneur's performance drops, he will get sacked just as easily. Then just let him (or her) try to reach a similar level again. We must also point out that what we really want is to dispense with the option arrangements, whereby the administrator's income depends on the rise in prices. These arrangements are considered an important cause of the creative bookkeeping of companies such as Enron, WorldCom and Ahold.

What is an acceptable salary for a top manager? For the general public, any amount with five or more zeroes is a top salary. The general public is not able to follow the considerations of the Board of Commissioners of Ahold or the administration of the Heart Foundation. Ahold has weighed a number of possibilities and is happy to be able to draw in a top manager who is able to save the company that is at the edge of the abyss. The administration of the Heart Foundation is happy that they were able to attract the cardiologist who can speak on equal terms with the researchers who receive money from the foundation. That cardiologist has passed over a royal income as a medical specialist in order to accept the position of director.

However, the entrepreneur is increasingly becoming a public personality. The collector must be motivated to collect door-to-door for the Heart Foundation. The consumer must be prepared to pay the somewhat higher price of Albert Hein products. With Albert Hein stamps, the broad public saves for Ahold shares. People place a direct relationship between their own situation and the conduct of the top manager. They want to be able to trust him. The public wants the leaders of organizations who are responsible for business decisions that bring about major social consequences to think from a social perspective as well. In this respect, entrepreneurs are beginning to resemble ministers. They are expected to occupy their position purely in the public's interest. A personal advantage damages that ideal. A too high salary and other personal advantages are quickly seen as misuse of the position of the office.

For businesses, this discussion brings up a difficult problem. Negotiations are conducted with those involved on the terms of employment. The cost-benefit analysis is made behind the closed doors of the Board of Commissioners. Only the Board of Commissioners has any insight into the 'labour market for top managers'. At the same time, account must be taken of public opinion. The transparency that is required 
within the framework of Governance results in everyone looking over the shoulders of the Board of Commissioners. Can and may the Board of Commissioners allow themselves to be led by the perception of the broad public?

\section{Honest coffee}

Pressure groups call upon the major coffee roasters, such as Nestlé, Kraft, Sara Lee/DE and Procter \& Gamble, to pay an 'honest' price for the cultivated coffee beans. By purchasing directly from coffee growers, the intermediate trade can be bypassed and a fair compensation can be paid. The coffee growers form the weakest link in the coffee chain and deserve protection. In the meantime, a few certificates have been developed to ensure that the coffee in question is produced in a responsible manner. This means that a fair compensation is paid to the growers and that there is no damage to the environment. It concerns, among others, the Max Havelaar quality mark, the Utz Kapeh certificate and the Rain Forest Alliance certificate. A part of their coffee is purchased by various coffee roasters in this manner.

The coffee roasters point out the heavy competition, however. If consumers are not prepared to pay the extra costs for the added value of 'honest' coffee, no company can survive. Max Havelaar can allow itself a higher price. It is a niche player and can appeal to idealistic consumers who are willing to pay a bit more for their coffee. Stability of the flavour of the coffee blends also plays an important role. Because the major coffee roasters buy from all over the world and have no admeasurement contracts with certain suppliers, they can ensure a stable flavour. The major coffee roasters serve roughly 10 to $15 \%$ of the world market. With such a scope, you do have to aim at the broad public. Then the stability of the flavour and price play an important role.

The big coffee roasters also state that the low coffee price is ultimately caused by overproduction. Simply said: too much is produced. This is partly due to the end of quota arrangements such as those that applied until the end of the ' $80 \mathrm{~s}$. When the major coffee roasters pay more than the market price, this stimulates even more overproduction. What is the responsibility of the major coffee roasters?

\section{Obesity}

Unilever, the fast-food chains and the soft-drink industry are being called to account for making people fat. Obesity is spreading. It is not only a problem in the Western countries; developing countries are also dealing with it. Worldwide there are 1 billion overweight people and 300 million people with serious forms of obesity. Obesity is now one of the leading causes of death. The illnesses caused by obesity cost the Dutch society between 450 million and 2.2 billion Euros per year (Aan de Burgh 2004).

In the discussion, fingers are pointing at the food industry. They try to tempt us to eat hamburgers or ice cream or to drink soft drinks. Are the food concerns actually guilty, or should we blame the consumer? You are what you eat. Unilever top man Anthony Burgmans makes a connection with our altered lifestyle. Calorie intake has hardly increased over the last few decades, but only about half the calories have been burned during that same period. Burgmans: "I blame the electronics industry, because these days people watch television for four, five hours per day. I blame the automobile industry. I also blame the software industry. Thanks to them, children are busy with a PC two, three hours per day. I blame the government, because it is economizing and dropping gym class! Should I go on?" 
In California the political world has recently joined in the discussion of obesity as well. Here a link is made between the soft-drink industry sponsoring schools and the availability of a certain brand of soft drink at those schools. Thanks to the sponsoring, the schools can buy books and support poverty-stricken parents so that their children can participate in school activities. According to the critics, however, children, who are not very critical, are being influenced without them realizing it. Once accustomed to a certain brand, a child will not easily switch to a different product. This also unconsciously creates the image that soft drinks are healthy. The authority of the school is also reflected on the soft drink that is recommended here.

What is the responsibility of the food industry? Is the increasing obesity of the population the responsibility of the people themselves, or should the soft-drink industry and the fast-food restaurants bear responsibility here? Should restraints be imposed on advertising? Should there even be a tax on high-calorie food, something that has been seriously proposed and is already occurring in some countries?

\section{Striking aspects of the cases}

What does the discussion concerning top salaries have to do with the responsibility of the food industry for the obesity of children and the responsibility of the coffee roasters for the low wages of coffee growers? In analysing the cases, a number of matters come to the fore:

- Businesses are pinned with responsibilities that are in fact social responsibilities, in which the company only has a part - sometimes even a very small part. You can call the food industry to account for people becoming fatter, but obesity is initially related to our unhealthy lifestyle. You can blame the coffee roasters for the low coffee price for the coffee growers, while the leeway for the coffee roasters to pay higher prices for the coffee is also related to the willingness of the consumer to pay a higher price for 'responsible' coffee.

- In considering the responsibility of business, people are inclined to reason in 'black and white' terms. The responsibility lies either with the people who are overweight themselves (or the parents of these children), or with the company.

- In the discussions, people readily tend to reduce the complex relationships by singling out a certain connection and understanding it as a causal relationship. The advertising of the food industries, the profits of the coffee roasters at the expense of a fair price for the coffee growers, or the bonuses of the top managers are pointed out as the cause of the social problem.

- In the discussions resulting from the described events, values play an important role. The soft-drink industry's drive for profits is in conflict with the health of the youth. The value of the free market is in conflict with a fair reward for the coffee growers. The greed of the top managers is in conflict with a true representation of the reality in the business reports. It is always supposed that one social value is placed in a tight corner because (economic) interests are in play that form an impediment for the persons involved for doing justice to the social value. It is reasoned that a choice for the economic interests means a choice against the fundamental social value that is at issue.

- The social debate resulting from these matters is primarily aimed at looking for the guilty parties. When a company or person can be designated as the guilty one, everyone can lean back with a satisfied feeling. It is about the unreliable behaviour of one company or one person. This approach is understandable. It keeps the issue limited, and therefore manageable. The problem seems to be 
solved when we 'remove' the person involved or the company in question goes bankrupt or is totally reorganized. The 'grabby top manager' must disappear, the high-calorie food from the food producers must be kept off the shelves, and the coffee roasters must demand that the suppliers of their coffee pay a fair price. The 'flaw' must be removed. Then we can get back to the order of the day.

- By looking for guilty parties, it is also possible to set aside one's own responsibility. In all three cases, we are dealing with a social problem, whereby we are only too willing to clear ourselves as possible culprits. The concern for a healthy lifestyle is primarily the responsibility of those who consume fast food. The responsibility for the health of the youth lies primarily with the parents. We do not need to change our coffee-buying behaviour. In the example of the top salaries, the public at large is also to blame. At the end of the nineties, the stock market developed into a sort of pyramid game, whereby everyone wanted to profit from the internet hype. Businesses had to show profit gains exceeding $10 \%$, and preferably with even better profit expectations. That put enormous pressure on businesses and their management. This can be attributed to the bonus-and-option culture.

- If we seek the structural causes in the discussion regarding these affairs, they are generally found in the shortfalls of legislation and the social and internal business control systems ${ }^{1}$. Businesses seek the limits of what is legal and will even exceed them if they are not kept under control via laws and an efficient monitoring system. Therefore, in the debate there is a request to curb the advertising of the soft-drink industry and to levy extra taxes on high-calorie food, and the political world will be pressed to take measures against exorbitant salaries.

- Businesses themselves tend to look for the solution in technology. They are diligently looking for food with fewer calories. Through certificates, the farmers and the intermediary trade must demonstrate that the coffee is produced in a socially and environmentally responsible manner.

\section{The responsibility of businesses for the public interest}

The examples fit within a larger picture. In fact, these examples concern the responsibility of businesses to contribute toward solutions for social issues. Looking for guilty parties distracts from the fundamental question facing businesses and, in fact, society as a whole, at this time. Also as regards major social problems, such as climate change, the war against poverty, driving out corruption, the AIDS problem in Africa and, for example, safeguarding biodiversity, businesses play a role. Businesses are called to account on these issues, and various businesses give signals that they experience responsibility in this regard. In the Communist countries, it was the government that was supposed to deal with these issues via a comprehensive control system. Until recently in many Western countries, people relied on a combination of market forces and a corrective government. The Communist system collapsed. But also in the Western countries, where the government had to steer businesses in the right direction via laws and incentive schemes, it seems that the government 'bit off more than it could chew'. Privatization and deregulation resulted in a stronger faith in market forces. Public pressure must stimulate businesses to take responsibility. A consequence of the privatization and deregulation is that social factions no longer turn to the government to steer businesses through legislation. These groups approach

\footnotetext{
${ }^{1}$ In fact, the reasoning here is based on a compliance strategy. See below.
} 
companies directly, or try to pressure businesses by appealing to public opinion. For businesses, it is difficult to work out how to deal with these questions. What is the responsibility of businesses, exactly? Where do the limits of responsibility lie? It cannot be that one company is responsible for all the wrongs in the world. And how can this responsibility be compatible with market-oriented thinking? True, a company needs the trust of the relevant social ranks. In this regard, we can speak of a 'license to operate'. Ultimately, there must be customers who are willing to pay the extra costs of corporate social responsibility, and shareholders must be willing to make risk capital available.

\section{Compliance and market thinking}

The compliance view on businesses is in fact seamlessly connected with the market thinking as it has developed over the last centuries in the Western world. In both models, there is actually no room for corporate social responsibility: businesses that, on their own initiative, take responsibility for social issues.

First, let us talk about market thinking. Adam Smith already stated that he has little faith in the good intentions of the entrepreneur. "I have never known much good done by those who affected to trade for the public good" (Of restraints upon the importation from foreign countries of such goods as can be produced at home 1776). $\mathrm{He}$ had more trust in the self-interest of the entrepreneur. Via an invisible hand, it would ultimately lead to optimally serving the general interest: "... every individual generally, indeed, neither intends to promote the public interest, nor knows how much he is promoting it ... he intends only his own gain, and he is in this, as in many other cases, led by an invisible hand to promote an end which was not part of his intention. Nor is it always the worse for the society that it was no part of it. By pursuing his own interest he frequently promotes that of the society more effectually than when he really intends to promote it" (Of restraints upon the importation from foreign countries of such goods as can be produced at home 1776).

Market forces ensure that the businesses that can supply their products and services in the most efficient manner will ultimately survive. By using a market model as the basis for finding solutions for the major social problems, consumers and shareholders must in their buying decisions consider the manner in which businesses adopt social responsibility. Moreover, businesses are seen as amoral instruments of the final buyers. The use of certificates and hallmarks (Max Havelaar, Eko hallmark) is based on this line of thinking. The question, however, is whether the knowledge and the insight of consumers can be trusted in the complexity of the connections, and whether it is realistic to expect individual consumers and shareholders to embrace social interests in their buying considerations and investments, and also be able and want to embrace them. In the cases of the harmful effects of frequent consumption of soft drinks or visits to fast-food restaurants, the meagre coffee prices for the coffee growers and the pressure on businesses to show high profit figures, the role of the general public is systematically ignored. Faith in the awareness of the general public (through market forces) falls short, particularly when it concerns unintended side effects of the choices made. Market forces presume that people are driven by their own self-interest, and that what is valuable to the consumer or shareholder is unambiguous, and that you can clearly see a direct relation between the decision to buy and invest and the honoured value.

There is also a second way in which market forces could lead to solving social issues. By incorporating the social costs (externalities) in the price of the product, the 
price mechanism can contribute toward solving the social problem. One example of this is emission trading. On the basis of the Kyoto protocol, The Netherlands and other countries have committed themselves to bring about reductions in emissions (the main cause of climate change). By setting a price on emissions and making them marketable, one initiates emission trading. No appeal is made to the social responsibility of the consumer, nor to the social responsibility of the entrepreneur. In fact, the system offers room for entrepreneurship. However, in this sense, market forces can only to a limited degree offer a solution for the major social issues. Not all social issues can be expressed as a price or reduced to unequivocal causes on which a price can be set. The problem of obesity is an example of this. The value of health cannot be expressed in a price. But you can show the costs of health care resulting from unhealthy eating habits. What is more, it concerns a combination of causes (too little exercise and the wrong eating habits) in which many parties play a role. In addition, market forces presume an (international) legal system that ensures that the parties will observe the rules of play. The Kyoto protocol and the United States' reaction to it demonstrate the problems involved.

The compliance point of view is based on a negative image of man and organization. Organizations and the people within them tend to pursue their own interests, even at the expense of others. The soft-drink industry's sponsoring of schools is seen as a sophisticated marketing technique. The health of the youth is secondary to the business's drive for profits. The ultimate explanation of the behaviour of businesses is the greed of the top management. Yet this behaviour can be controlled via rules, monitoring compliance and sanctions. The Sarbanes-Oxely legislation and the developments concerning Corporate Governance can be understood on the basis of the prevailing compliance thinking ${ }^{2}$.

The compliance approach is linked with the market approach. Like the market model, the compliance approach does not trust the business's own responsibility. Thanks to competition, maximum prosperity is realized. It is tempting to regard steering via (democratically adopted) laws and a (democratically chosen) governmentcontrolled system of laws, rules, procedures and sanctions as a complement to the market forces. Through rules and sanctions, the 'free-rider behaviour' of businesses and the management within them can be prevented. This is how optimal welfare is realized.

A compliance approach cannot offer a solution in the examples described above, however. In order to steer businesses by means of laws, one must be able to understand the problems as simple causal connections, whereby responsibility can be clearly ascribed to certain actors and the effects of certain actions will provide insight beforehand. Moreover, laws, rules and monitoring systems are always running a step behind.

There is also something else more fundamental going on with the compliance approach. The compliance approach eliminates responsibility from businesses and from natural persons - managers, shareholders and consumers. You act responsibly as a citizen when you adhere to the laws, rules and procedures. The compliance approach does not call upon businesses and natural persons to account for their own responsibility. If you want to ensure that the social actors contribute toward solving social issues, then it must be possible to lay down the required behaviour in concrete tasks and roles in a sound manner. A characteristic of the sketched social problems is,

\footnotetext{
${ }^{2}$ Here we are following the distinction that Lynn Sharp Paine (1994) makes between an integrity strategy and a compliance strategy
} 
however, that there are dilemmas. What is required cannot be unequivocally set down. Moreover, there is a certain dynamic. Solutions are found by trial and error. In order to find solutions to major social issues that have been pointed out - such as the problem of obesity and other public-health issues, the problem of climate change, partly due to increasing mobility or the trust in the business world as a condition for economic development - the compliance approach falls short.

\section{Dilemmas, value pluralism and social support ${ }^{3}$}

Previously, I had already commented that in the debate on the sketched affairs, the complex connections are often reduced to one area of tension between the social or moral values (public health, healthy environment, transparency of the business functions, spreading prosperity, preserving biodiversity, sustainable use of energy sources, etc.) on the one hand and economic interests on the other. The social value is in a tight spot, because economic interests place too much pressure on those involved. Actually, however, there is a conflict between several values. With the problem of obesity, it concerns the consumer's choice, the interests of the schools, for example, the economic interests of the food industry (employment, interests of suppliers, shareholders, authorities) and public health care. In the bookkeeping affairs, it concerns the freedom of top managers to negotiate their terms of employment, the proper functioning of the global economy and a true representation of reality in the business reports. It is not one value that is under pressure; it is actually the various values that are all legitimate. Different values have economic sides. Prosperity and the proper functioning of the economy are social values. Just like the other social values, these values strive to have priority over the conflicting values. In fact, we are seeing a cluster of dilemmas, whereby different values are asking for priority.

An important characteristic of the described social issues is that there is no agreement on the best solution. All parties involved define the problem from their own perspective, assess risks in different ways and value the interests at issue in a different way. More accurately: each party involved ascribes a different weight to the values that are at issue. This is why the social issues mentioned cannot be understood merely as technical problems. It also concerns accepting the consequences of certain choices.

However, it also concerns the acceptance of the choices by the people who experience the consequences of the social decisions. I accept a certain nuisance, knowing that major interests are at stake for society. As a child, we lived very close to a railroad. For us, the noise nuisance was a given. You did not even hear the train that thundered by once every half-hour. In fact: when the train did not come one time, you even missed something. We accepted that train and also the growing number of trains on that line. The railway was already there when we came to live there. We realized that rails had to be somewhere. What is more, certain necessary precautions were taken, such as safety measures, to limit the nuisance to a minimum for the people living in the neighbourhood. The encroachment on the value that the rural quietude meant to us was accepted because it served important social values. When businesses consider the stakeholder dialogue, social reporting and the verification of it as a technical solution of the social issues, then they misjudge the nature of these issues. Reducing the calorie content of food or reducing the number of decibels of aeroplane

\footnotetext{
${ }^{3}$ See also Chapter 2 in Kaptein and Wempe (2002)
} 
noise is not enough to achieve social acceptance. I call such an approach the engineer's interpretation of corporate social responsibility.

Corporate social responsibility is aimed at finding widely supported solutions for social issues, with ethics playing a crucial role. Stakeholders will only accept the burdens of social choices when they see the truest possible respect for the values of the victimized stakeholders and a fair consideration of the pluses and minuses for all parties involved.

An appeal to ethics is not sufficient, however. It also concerns an approach that is suitable for understanding the complex social issues. In my view, prevailing ethics do not make the grade in this regard. The classic ethic theories, such as the consequentialist and principalist ethical theories, are all of a monistic nature. They are all based on one dominant value or a hierarchy of values on the basis of which behaviour can be judged. In fact, these theories support the technical approach of corporate social responsibility (CSR) that I criticize, and they cannot work with the core of the CSR issue: the plurality of values and the (inter)subjective character of the values that come into play. Several values can be in effect at the same time. When a society makes a decision at a certain moment and thereby chooses for a value that lies at the basis of that interest, this does not mean that a choice is made are against the other values. Moreover, values are always related to the assessments of the persons involved.

Value pluralism rejects the monistic view on moral norms and values. In addition, one must take care not to become caught in the pitfall of moral relativism. According to value pluralism, there are various fundamental values that cannot be reduced to one universal value. It is possible that they can clash with each other and that they can even be incompatible. Different values can be in effect at the same time. Sometimes it is possible to indicate priorities. However, it is often not possible to determine what 'the' right answer is. There is not one decisive criterion on the basis of which we can ultimately choose. It may not be concluded from the existence of value pluralism that all opinions and the values that lie at the basis of them which the various stakeholders hold are all equally good. The impossibility of indicating priorities can be caused by the fact that our knowledge is not yet sufficient for properly weighing up the values that are in force. Another important reason for the impossibility of indicating priorities is that values cannot be compared.

\section{The moral compromise}

Van Willigenburg (2002) recognizes, following Martin Benjamin (1990), the impossibility of determining which values deserve priority, an argument for striving towards a moral compromise. Reaching a moral compromise does not mean that moral values are the object of striking a bargain and that the persons and organizations involved compromise themselves and make concessions on their own integrity. For an airline, the safety of the passengers is one of the most important values. For this reason, most airlines demand a certain number of hours from all the crew members before flying, that no alcohol is consumed and that alcohol tests are conducted. At the same time, the respect for their personnel requires that the airlines assure their privacy. In order to do justice to both values, alcohol tests are usually only conducted on the captains, with the assurance that the test will not be used for other purposes. These airlines accept a certain risk by only subjecting the captains to the test and limiting the use of the test to the purpose for which it is conducted. The pilots accept a certain invasion of their privacy. Reaching a moral compromise can be in the 
form of negotiation: give and take by the parties involved. According to Van Willigenburg, two requirements must be set within that process of moral negotiation. In order to endorse the autonomy of all those involved, they must endeavour to achieve the most commensurate possible division of pluses and minuses, whereby compromises are made from the different sides. In the example of the alcohol test, all parties compromise. The second requirement of moral compromise is actually at odds with the demand of seeking a proportional distribution. For certain participants in the discussion, some values are so important that they are experienced as determinants of their identity. In seeking a compromise, a more than proportionate weight must be ascribed to such identity-determining values. Within businesses, a discussion can arise about the smoking behaviour of the personnel and the resulting second-hand smoke for the other staff members. For people who are asthmatic, a healthy work environment is so important that a compromise must at least ensure a smoke-free environment for the personnel who are bothered by smoke.

\section{Social surplus value}

From a monistic ethics perspective, not being able to choose between values is seen as something negative, as a shortcoming of ethics. However, tensions between values can also form a source of value creation. Value conflicts are then a challenge for those involved to seek better solutions that do more justice to the values there are at issue.

Such tensions are found on all sorts of levels within and around organizations. People fulfil various roles which sometimes involve conflicting expectations. This is intrinsic to life. By working as an employee for a company, the role conflict becomes more complex and weighty. An employee must satisfy a customer, is perhaps a member of the Works Council, wants to treat his colleagues with loyalty but remains the father or mother of a family, has family and friends, and is a member of all sorts of associations. A complex of interests and other role conflicts are the result. Within an organization, different people have different functions. The marketer of a pharmaceutical company is eager to make the most of all the opportunities to put the company's products and services in the limelight. The doctor will be reserved with respect to the marketing techniques and promises that are made in advertising claims. The personnel manager will look primarily at the company's ability to attract new personnel and, for example, have an eye for the personnel's scope to develop their abilities. The security officer worries about information leaks and computer theft. By installing gates, hiring doorkeepers and monitoring the clean-desk policy, he attempts to realize these goals. Various officials are involved in the organization in different ways. Various values lie behind it all. The business deals with a multitude of stakeholders: employees, customers, shareholders, suppliers and, for example, authorities. Each with their own expectations and assessments, and all legitimate. A bank that considers the career opportunities for the employees to be of great importance will have to offer an account manager a new position, also when it means that the customers he serves must then build up a relationship with the new business representative. In society, all sorts of different parties deal with each other. The environmentalists campaign against the encroaching business parks and new residential areas, to the detriment of nature. Businesses want space in order to expand. Local governments must think about tourism, the development of the local economy, housing for their own population and, of course, preserving the natural beauty. 
These tensions can be designated as the 'dirty- and many-hands dilemma'. It concerns tensions that occur in the form of dilemmas for managers in daily practice. Together, these three types of dilemmas form the condition under which doing business is possible. As soon as one starts co-operating within a business context and bring products and services onto the market, these three types of dilemmas come about. These are real dilemmas, in the sense that fundamental value conflicts lie behind those tensions. At the same time, within the business context there is often a need for negotiation. Businesses and managers who act on behalf of the business can deal with these tensions in four ways:

They can ignore the value tension. Ultimately, the social (or organizational) field of influence will be the decisive factor for the outcome.

They can try to control the value tension by declaring one of the values as the decisive one. This is often a one-sided occurrence, and power is the deciding factor that determines the choice of the value to be maintained.

They can agree on a moral compromise. The moral character of this compromise depends on the questions whether people are striving toward a fair distribution of pluses and minuses and whether account is taken of values that determine identity and the rights of the non-articulate stakeholders.

They can endeavour to rise above the value tension by looking for a situation in which both values can be considered the same time, which will ultimately result in added value for those involved.

With respect to the dilemmas confronting managers in their daily work, it is possible in many cases to look for optimal situations whereby the different values that come into play are thought up together as well as possible. For the process aimed at combining conflicting values, Hampden-Turner and Trompenaars use the term 'reconciliation' (Hampden-Turner and Trompenaars 2000). This 'simultaneous thinking of incomparable or conflicting values' is often possible by breaking through unconsciously and implicitly maintained system limits and by ensuring that we do not only look at the here and now. Questions that bring the dialogue partners on the track of reconciliation are: "Is it possible to pursue one's own values by realizing the values of the other?"; "What is the value in the somewhat longer term?"; and: "What role will the parties involved play in, say, five years?". Reconciliation of the conflicting demands can consist of a straightforward recognition of the impossibility of meeting all the set requirements, expressing remorse, sympathizing with the victim, striving to limit the damage and looking for compensation. It can also entail looking for creative compromises. This approach often means that people allow themselves to be vulnerable, are willing to learn from their mistakes and are open to better ideas.

\section{Transition management}

In fact, the described examples require a social turnaround, a transition in society. This involves social changes that can only occur when a great many parties in many places more or less decide at the same time to support one another. The obesity problem makes primary demands of parents regarding their own children, and of the consumer regarding his or her own health. It requires an active contribution from education and health care. And the food industry, the computer, software and electronics companies and the automobile industry must contribute as well. In the first place, it requires awareness of the dilemma and insight into the values that are vying for priority. All parties involved must consider how they can make a contribution toward the solution. Characteristic of such a major social turnaround is that it cannot 
be realized according to a preconceived plan. It is about many small steps that must be taken in many places, independent of each other, but still more or less on a parallel level. What this transition will look like exactly and where we will wind up is not immediately clear. In this connection, we can use the metaphor of 'the trip south'. We know the direction: to the South, to an honest distribution of pluses and minuses between North and South, toward healthier eating patterns. Where we will wind up is still unknown. Whether it is Barcelona, Rome or Athens is not totally clear. We will have to see whether we must seek the solution in food with fewer calories, better food for babies, more exercise and more self-control by the consumer. We are looking for enthusiastic travelling companions with a feeling for adventure and who want to join us on our way.

Transition management (Rotmans 2003) is the term that is used to explain the process of facilitating such a social turnaround. In fact, all social actors can function as transition manager. The traditional view of the government is that it formulates social goals, which it then attempts to realize using the available policy instruments, such as legislation, taxes and subsidies. Now that the belief in feasible society has been abandoned, it is society (businesses, social groups and the public) that must formulate the concrete goals. This occurs step-by-step, and in many places at the same time. The government, but also businesses or social organizations, can facilitate that process. They can recognize initiatives that go in the desired direction, stimulate parties to 'find each other', help remove obstructions hindering the successful development of these initiatives, and they can make a start possible where financial resources are needed. In concrete terms, it is about looking for likely initiatives aimed at the desired change, for which there is support in the market.

\section{Professional ethics and social changes}

In order to find solutions to the sketched social issues, market forces and government regulations fall short of the mark. These issues require a new approach that offers room for value pluralism and relies on social support. In fact, we are looking for a new form of social organization. In addition to the market mechanisms and competition, and besides a corrective and steering government, a new form of social organization will exist, in which there is co-operation between businesses, governments and social organizations. Only through co-operation can the necessary social turnarounds be realized.

This places high demands on the professional. That applies to the manager, the marketer and the researcher. Solutions cannot only be sought in technology. It is quite possible that developing low-calorie food will have an adverse effect. People will think that they can eat even more. A well-intended contribution from businesses aimed at solving the obesity problem can - if the possible adverse effect of the solution becomes visible - be understood as a sophisticated trick from companies aimed at making profits at the expense of people's health. It is possible that setting environmental requirements and social requirements for the coffee middlemen will only wind up helping the big coffee growers at the end of the chain to survive, and that the small growers will be edged out via the competition.

Consequently, the professional will have to be a party in the social debate. He will have to be open to the signals concerning the company, but will also have to share the experienced dilemmas. Only in this way can awareness of the major social issues among all parties involved develop, as well as attunement between all these 
independent actors, so that the solution to these social problems can be brought closer by, step by step. The professional must develop himself into a transition manager.

\section{References}

Aan de Burgh, M., 2004. Globesity: de wereld wordt te dik: wie is verantwoordelijk. NRC Handelsblad (23 January 2004).

Benjamin, M., 1990. Splitting the difference: compromise and integrity in ethics and politics. University Press of Kansas, Lawrence.

Hampden-Turner, C.M. and Trompenaars, F., 2000. Building cross-cultural competence: how to create wealth from conflicting values. Yale University Press, New Haven.

Kaptein, M. and Wempe, J., 2002. The balanced company: a theory of corporate integrity. Oxford University Press, Oxford.

Of restraints upon the importation from foreign countries of such goods as can be produced at home, 1776. In: Smith, A. ed. An inquiry into the nature and causes of the wealth of nations. Vol. 4. Of systems of political economy. London, Chapter 2.

Paine, L.S., 1994. Managing for organizational integrity. Harvard Business Review, $72(2), 106-117$.

Rotmans, J., 2003. Transitiemanagement: sleutel voor een duurzame samenleving. Van Gorcum, Assen.

Van Willigenburg, T., 2002. Bedreigen morele compromissen onze integriteit? In: Paper presented during the workshop Integrity in theory and in practice, organized by the Onderzoekschool Ethiek, Vrije Universiteit, Amsterdam, 8 November 2000. 